\title{
The Effects of Representation on Idea Generation and Design Fixation: A Study Comparing Sketches and Function Trees
}

\author{
Olufunmilola Atilola, Megan Tomko, Julie S. Linsey
}

Woodruff School of Mechanical Engineering, Georgia Institute of Technology, Atlanta, GA 30332, USA

\begin{abstract}
Representations in engineering design can be hand sketches, photographs, CAD, functional models, physical models, or text. Using representations allows engineers to gain a clearer picture of how a design works. We present an experiment that compares the influence of representations on fixation and creativity. This experiment presents designers with an example solution represented as a function tree and a sketch, we compare how these different external representations influence design fixation as they complete a design task.. Results show that function trees do not cause fixation to ideas compared to a control group, and that function trees reduce fixation when compared to sketches. Results from this experiment show that function tree representations offer advantages for reducing fixation during idea generation.
\end{abstract}

\section{Keywords design fixation; engineering design; conceptual design; design activity; creativity}

Corresponding Author

Julie Linsey

julie.linsey@me.gatech.edu 


\section{The Effects of Representation on Idea Generation and Design Fixation: A Study Comparing Sketches and Function Trees}

Engineering design entails and implements a range of design representations to convey and document information; these include text descriptions, sketches, line drawings, photographs, computer-aided designs (CAD), and functional models. Previous research (Adler \& Davis, 2007; Goldschmidt, 2007; Larkin \& Simon, 1987; Linsey, et al., 2011; Linsey, et al., 2010; Yang, 2009) has explored the use of representations in problem solving and concludes that effective diagrammatic representations (e.g. CAD, sketches, photographs, line-drawings, etc.) hold many advantages over detailed textual representations. This research has determined that diagrammatic representations explicitly present the relationship between the visual depiction and elements of the problem by co-locating necessary and useful information in the representation (Larkin \& Simon, 1987). From processing this grouping of information, the designer avoids two cognitively expensive tasks associated with a purely textual representation: (1) having to match and understand symbolic labels and (2) searching for specific elements within the problem statement needed to establish a problem-solving inference. Seemingly, due to these disadvantages of textual descriptions, designers frequently prefer diagrammatic representations for engineering ideas and designs.

Despite the long-standing popular use of sketching for early idea conceptualization, CAD renderings and photographs are increasing in use due to advancements in technology. Due to the advent of computer modeling and drafting packages, i.e., CAD, which are readily available, engineering students tend to sketch less (Grenier, 2008; Schmidt, Hernandez, \& Ruocco, 2012; Ullman, Wood, \& Craig, 1990; Westmoreland, Ruocco, \& Schmidt, 2011). Grenier's study (2008) demonstrates that students pursue alternative representations to sketching as a form of design during the early stages of conceptualization. In a similar study, Westmoreland et al. (2011) analyze visual representations (sketches, line drawings, CAD, and photographs) for their use in Capstone Design and obtains comparable results. Westmoreland finds that students rarely use sketches until specifically prompted. Additionally, students are increasingly reluctant to submit rough sketches since they can quickly transform a sketch to a CAD drawing (Westmoreland, et 
al., 2011). Likewise, photographs are growing in popularity due to the availability of digital cameras and due to the ability to copy images from the Internet.

Functional modeling and decomposition is another method used for representing designs. However, functional modeling represents a design very differently than the diagrammatic representations already discussed. As the name implies, functional models and function trees list the functions on a design. These functions are in the form of action verbs necessary to system objectives and are listed in a top-down manner. Conceptualizing, defining, or understanding a product or system in terms of function is a fundamental aspect of engineering design (Otto \& Wood, 2001; Pahl \& Beitz, 1996; Pahl, Beitz, Feldhusen, \& Grote, 2007; Ullman, 1992; Ulrich \& Eppinger, 1995). Functional modeling provides an abstract yet direct method for understanding and representing a product's overall function (Hirtz, Stone, McAdams, Szykman, $\&$ Wood, 2002). Functional models serve as an asset in the idea generation process, as well as for storing and extracting design knowledge from existing products (Altshuller, 1984; Murdock, Szykman, \& Sriram, 1997; Stone, Wood, \& Crawford, 2000). Viola, et al. (2012) state that functional models are advantageous when used in engineering idea generation because the abstract view of function trees fosters the search for alternative solutions and as a result, avoids biased ones. The function-means tree method by Dym and Little (Dym, Little, Orwin, \& Spjut, 2004) is an example of how function trees or diagrams are used in the idea generation. Functions (what the design will do) and means (how the design will do it) are listed in a functional model; the function tree alternates between functions and means until a reasonable termination point is reached.

While allowing engineers to convey information to other designers, these representations permeate the examples that designers use when developing new ideas. Studies show that designers fixate to examples given to them whether the examples are in the form of sketches, line drawings, photographs, or physical models (Cardoso \& Badke-Schaub, 2011; Cardoso, BadkeSchaub, \& Luz, 2009; Christensen \& Schunn, 2005; Kiriyama \& Yamamoto, 1998; Linsey, et al., 2010; Purcell \& Gero, 1996; Viswanathan \& Linsey, 2010; Viswanathan \& Linsey, 2011; Viswanathan \& Linsey, 2012a, 2012b; Viswanathan \& Linsey, 2013a). Previous studies on design fixation compare other representations, including line drawings to photographs (Cardoso \& Badke-Schaub, 2011; Cardoso, et al., 2009), sketches to physical models (Viswanathan \& Linsey, 2013b; Youmans, 2011), and sketches to textual representations (McKoy, Vargas- 
Hernández, Summers, \& Shah, 2001). All of these studies present poor examples to participants in order to reveal where design fixation negatively influences the design process.

This paper presents an experiment that investigates how externally imposed examples of function trees and sketches influence design fixation, design feasibility, and design quality. Understanding these aspects of idea generation will improve the process leading to a final design product. The experiment examines the influence that function trees and sketches have on how designers copy features in an example, which depends on the type of representation provided to the designer. This paper explores the theory that (1) function trees have greater reduction in fixation than sketches during idea generation and (2) function trees produce higher quality designs. In the following sections, we review the related prior work on design fixation and the impact of various representations or visual stimuli on design.

\section{BACKGROUND}

In the engineering design process, conceptual design is the front-end phase that relies on favorable idea generation. Idea generation can be defined as the process of generating, developing, and communicating ideas, where an idea is understood as a basic element of thought that can either be visual, concrete, or abstract (Jonson, 2005). During the conceptual design stage, engineers consider numerous possible solution concepts and ideas (Pahl \& Beitz, 1996) while addressing potential feedback elicited from end users or design stakeholders regarding the current or needed product. Hence, the engineers can decide which ideas should be further developed or pursued (Schrage, 1999). In order to have an effective idea generation process, it is necessary to abstract the essential problem or design requirement, establish relevant function structures, search for suitable working principles, and then combine those principles into a working design (Pahl \& Beitz, 1996).

Idea generation in the design process begins in the mind's eye (Ferguson, 1992; Fish \& Scrivener, 1990; Goldschmidt, 1991). The representation of ideas to the designers directly influences idea generation; visual representation and the visual experience as a whole allow new ideas to be created in the mind and thus explored in the conceptual design process (Fish \& Scrivener, 1990; Goldschmidt, 1991). In this section, we discuss the differences among the various representations utilized in idea generation.

\subsection{Representation in Idea Generation}



CAD, photographs, or even verbal and textual representations. Gestures may also be a form of representation as they are often considered valid evidence of language and cognition (Hostetter \& Alibali, 2008). Each conveys different types of information. This paper focuses on sketching and function trees/modeling, so we will focus mainly on sketching in this section. We discuss functional modeling in the next section. A sketch is a preliminary, rough, visual design representation of something without detail for the basis of a more finished product (Pei, Campbell, \& Evans, 2011). It is usually executed rapidly and without concern for detail in order to capture a general idea; only key elements of the design are presented (Pei, et al., 2011; Westmoreland, et al., 2011). A sketch requires composition without aiding instruments, such as a straight edge. This differentiates it from a line drawing which is composed of a line created by hand but with the aid of assistive instruments; a line drawing can also be created with a computer (Westmoreland, et al., 2011).

During the idea generation process, we note that there are two modes of presenting these representations. The first mode of representation is external where designers view examples as stimuli for inspiration in the design task. The second mode of representation is the method where the designers choose to represent their ideas, i.e., self-generated representations. In this study, we are only concerned with varying external representations to examine their influence on design fixation; we maintain a constant self-generated mode, as sketches, for the experiment.

In group idea generation meetings, it remains a common practice to combine sketches with text or written language (Van der Lugt, 2005). Various studies have been completed regarding the role of sketching in design and conclude that sketching during idea generation improves the overall quality and realism of the design (Macomber \& Yang, 2011; Yang, 2009; Yang \& Cham, 2007). Even with a decline in the use of sketching among engineering students, sketching offers several advantages over other representations (Westmoreland, et al., 2011). Advantages include the fact that sketching is economical, simple, and easy to correct and revise (Jonson, 2002) and also promotes creative thought, which stands as a critical aspect in generating concepts (Goel, 1995; Goldschmidt, 1994). The designer is also able to obtain immediate visual and kinesthetic feedback from a sketch (Contero, Varley, Aleixos, \& Naya, 2009). 
Additionally sketches possess the advantage of being inherently ambiguous with regard to recognition (Contero, et al., 2009; Goel, 1995; Jonson, 2002; Stacey, Eckert, \& McFadzean, 1999). Sketches lack regularity and contain a certain type of looseness or "sketchiness," which makes them prone to having different interpretations. Rather than inducing uncertainty or confusion, ambiguity in design sketches can be a source of creativity since sketches allow designers to re-perceive and re-interpret figures or images (Tversky, et al., 2003) or to interpret the figures or images differently from other fellow designers or team members (Shah, 1998). Tversky et al. (2003) explain that sketches hold the created constructions in view of the designer, freeing the mind to examine and evaluate. Their findings also show that novice and experienced designers formulate new inferences from even their own sketches.

Studies show that both the amount and type of information that designers access varies when interpreting different types of representations (Casakin \& Goldschmidt, 1999; Kavakli \& Gero, 2001, 2002; Kokotovich \& Purcell, 2000; Menezes \& Lawson, 2006; Suwa \& Tversky, 1997). (Reid, MacDonald, \& Du, 2013)

In the aforementioned studies, the researchers explore how the type of representation affects a designer's creativity during idea generation in the design process and how the different external representations influence design and provide information to the viewer. In this paper, we specifically focus on the latter and the effect on design fixation, i.e. how external representations affect ideation and creativity.

\subsection{Functional Models in Idea Generation}

In efforts to complete a design task or satisfy customer design requirements, designers generate functional models in order to emphasize the abstract purpose of the product or design, which is necessary for meeting underdetermined needs (Dorst, 2003), which is most always the case, or in rare cases, pre-determined and complete customer needs. Although functions are rarely used or seen in engineering practice, they are a fundamental part of many prescriptive methodologies (Eckert, Ruckpaul, Alink, \& Albers, 2012). By first mapping the design requirements to functions, the engineers may systematically explore more solutions to the presented problem or need (Ullman, 1992). More specifically, one type of functional model, otherwise known as function trees, consists of a hierarchical structure that begins with high-level functional requirements and descends into lower-level detailed functions (Eckert, 2013; Otto \& 

material and signal flow-based functional models (Otto \& Wood, 2001; Pahl \& Beitz, 1996). We choose to evaluate fixation with function trees because they contain multiple levels of functional abstraction that have the potential to reduction fixation whereas flow-based functional models do not show multiple level of abstraction in the same diagram. Function trees are more intuitive and easy to generate (Eckert, et al., 2012), compared with function structures. Function trees and models are often integrated into the conceptual stages of the design process because they encourage the designer to focus on the intended use and purpose of product rather than on the physical solution (Caldwell \& Mocko, 2012). This could prove to be advantageous by allowing designers not to focus on or to de-fixate from specific features; however, prior to the studies presented and discussed in this paper, testing has been limited regarding the impact of function trees on designers' fixation

Function trees typically represent a design in a functional view as opposed to a more physical view, e.g., CAD, sketch, photo (function trees can sometimes relate to the physical view in the sense that a functional model is a commitment to a solution architecture). These two complimentary views convey different information in the sense that there first needs to be a systematic structure of desired functions and effects, which is necessary for explaining the behavior and physical realization of a design (Zha \& Howlett, 2006). In other words, the functional view focuses on what the system must do to produce the required operational behavior, whereas the physical view focuses on how the system is constructed (Press, 2001). We would like to note that while function and physical embodiment are distinct, in some cases a physical affordance gives access to functionality (Hartson, 2003), i.e. the physical nature of the object, by default, reveals its function.

Function trees are advantageous in engineering design because they provide a wellrepresented graphical overview of the systems requirements (Viola, et al., 2012). Pahl et al. (2007) suggest that designers could potentially have the ability to better explore the solution space since functional models allow functions to be linked in several ways, e.g., function trees, function structures/function flow diagrams (Otto \& Wood, 2001), and functional analysis and allocation (Manning, 2013). More information on function trees and functional modeling in engineering design can be found. 
The experiment in this paper will investigate the effectiveness of function models, specifically function trees as a type of representation in idea generation process for solving design problems. To date, no studies have explored if externally introduced function trees fixate or not.

\subsection{Design Fixation}

Design fixation refers to the blind and sometimes counterproductive adherence of designers to example features and to their own initial ideas (Jansson \& Smith, 1991). Because examples act as external stimuli, they tend to make designers sensitive to the features and elements of the example. This is especially true for visual representations such as the ones previously discussed, i.e., CAD, photo, and sketch (Goldschmidt \& Smolkov, 2006). Though the intent for using these visual examples is to provide inspiration to the designers, designers' fixation to components of the example hinders their creativity. There have been numerous studies in engineering design and in psychology that deal with the topic of fixation (Christensen \& Schunn, 2005; Jansson \& Smith, 1991; Linsey, et al., 2010; Purcell \& Gero, 1996; Viswanathan \& Linsey, 2010; Wiley, 1998). Other fixation studies in psychology include functional fixation, which is a phenomenon where a mental block is created that inhibits a person from using an object in a new way (i.e. noticing an obscure feature of an object) that is necessary for solving the problem (Ashton, 1976; Duncker \& Lees, 1945; McCaffrey, 2012a; McCaffrey \& Spector, 2011). This phenomenon is similar to, and explains the underlying mental handicap that causes fixation in engineering design (Condoor \& LaVoie, 2007; Jansson, Condoor, \& Brock, 1993). McCaffrey (2012a, 2012b) suggests that researchers can systematically create a toolkit of innovation enhancing techniques by developing techniques that facilitate the designer's ability to notice obscure features and overcome obstacles to problem solving, such as design fixation.

According to Perttula (2006) and Liikkanen (2010), example exposure may not necessarily be detrimental. In the area of cognitive simulation, design and psychology researchers investigate possible benefits of examples or external stimuli and show that idea exposure can positively influence one's ability to produce ideas (Brown, Tumeo, Larey, \& Paulus, 1998; Coskun, Paulus, Brown, \& Sherwood, 2000; Dugosh \& Paulus, 2005; Goldschmidt \& Smolkov, 2006; Perttula \& Sipilä, 2007). Though these studies do not strictly measure fixation, results emphasize that examples do offer benefits to designers, such as aiding in the convergence of ideas in teams ( $\mathrm{Fu}$, Cagan, \& Kotovsky, 2010) and helping designers to determine whether existing ideas meet 

form of representation used in examples, e.g., sketch or CAD, appears to establish the conditions for fixation to occur. Thus, exploring the use of various representations in idea generation is very beneficial towards further understanding the dynamics of fixation in design.

In design fixation experiments, poor examples are typically used to induce fixation and to investigate trends across various parameters. Studies have shown that a poor example produces a higher amount of fixation compared to a good example (Fu, et al., 2010; Perttula \& Sipilä, 2007). Fixation studies with good examples measure both fixation and additional trends. For instance, Fu et al. (2010) measure how good and poor examples influence team convergence and how teams fixate to the examples given. In fixation studies that use poor examples to solely measure fixation to features of the examples, designers copy the poor features of an example without realizing that they are doing so (Linsey, et al., 2010; Viswanathan \& Linsey, 2013a, 2013b, 2013c). This is the exact definition of fixation and an undesirable engineering design behavior.

\subsection{Representations and Fixation}

Most previous research studies on design fixation use examples represented in only one form, predominantly sketches (Fu, et al., 2010; Jansson \& Smith, 1991; Purcell \& Gero, 1992). Only a few studies specifically explored the influence of different representations on design fixation. For example, Cardoso and Badke-Schaub (2011) investigate if different types of representation can affect and reduce design fixation. In their study, they compare a line drawing to a photo measuring differences in quantity, quality, and originality (using a "yes/no" criterion for originality). They found that both line drawings and photographs cause design fixation. There were no significant differences between the line drawing and the photo for quantity, quality, or originality. An experiment by McKoy et al. (2001), presented examples as a sketch or as text to teams in an undergraduate course and compared the design solutions to a design problem. The results from the McKoy study show that groups who received a sketch example had higher novelty and quality scores than the groups who received the text description of the example (this paper addresses and explains the quality and novelty metrics).

\section{EXPERIMENTAL OVERVIEW}

This paper presents an experiment designed to assess if, and to what extent, fixation occurs in engineering idea generation based on the representation of the example given. The participants 
were asked to solve a design problem with an example as an aid. Participants viewed a poor design example in the form of a sketch, function tree, or a combination of both, which are the designated conditions for the experiment. A control condition where participants did not receive an example was also included.

\section{EXPERIMENT}

This experiment was designed to assess the effectiveness of function trees on fixation to features of a design. We investigate if an example represented as a function tree reduces fixation compared to the same example represented as a sketch. We have an additional condition that includes both representations, and we check to see if there are any advantages in having a function tree present with a sketch.

Hypothesis 1: Fixation. Function trees will reduce fixation compared to sketch representations. This is measured with the quantity of non-redundant ideas.

Hypothesis 2: Quality. Function trees will produce higher quality designs because the required functional needs for the product are more explicit. This is measured with the quality metric.

\subsection{Design Task}

The design task given to the participants asked them to design a device that shells peanuts in developing countries. This task has been used in previous studies (Fu, et al., 2010; Linsey, Green, Murphy, Wood, \& Markman, 2005; Linsey, Markman, \& Wood, 2012; Linsey, et al., 2010; Viswanathan \& Linsey, 2011; Viswanathan \& Linsey, 2012b), and follows the same approach, i.e., description of the example design, time given to read problem, and time given to generate ideas. The chosen problem is practical, appropriate for engineers, and able to be solved in diverse ways. Figure 1 shows the problem description, customer needs, and instructions provided to the participants. The description of the example solutions given to the participants is described in later sections. In this experiment, the participants were provided with an incentive to create many solutions. They were told that the persons who showed superior effort in generating solutions would receive a bonus. 
Figure 1: Problem description, customer needs, and instructions provided to participants.

\subsection{Participants}

The participants in this experiment were sophomore and junior undergraduate students at the Georgia Institute of Technology. Thirty-nine juniors and twenty-two sophomores participated. The juniors and sophomore were evenly distributed across the four conditions in this study.

\subsection{Experimental Conditions}

In order to explore how various representations affect fixation and creativity in the engineering idea generation process, the participants were randomly assigned into four experimental conditions with each condition corresponding to a different type of representation, i.e., function tree or sketch. Each representation exemplified the same existing solution to a specified design problem: a peanut shelling device. The peanut sheller design problem is the Universal Nut Sheller, designed by inventor and humanitarian Jock Brandis (Brandis, 2012; Connors, 2008). Because the peanut sheller is considered to be easy to manufacture, cheap, sustainably powered (human energy), efficient, and effective, the design problem satisfies all of the customer needs and provides ample opportunity for design ideas to participants.

The four experimental conditions for this experiment were designed to measure the usefulness of function trees in reducing design fixation. A poor design-solution example, a gaspowered press sheller, was given to the participants in various representations according to the experimental conditions. Figure 2 shows the gas-powered press sheller and the solution description. Figure 3 shows the function tree of the example. The experiment conditions and the representations given were 
- Sketch: the example was represented in the form of a sketch (Figure 2)

- Function tree: the example was decomposed into a function tree (Figure 3)

- Function tree \& Sketch: the sketch of the example as well as the function tree were presented to the participants

- Control: no example or representation was provided

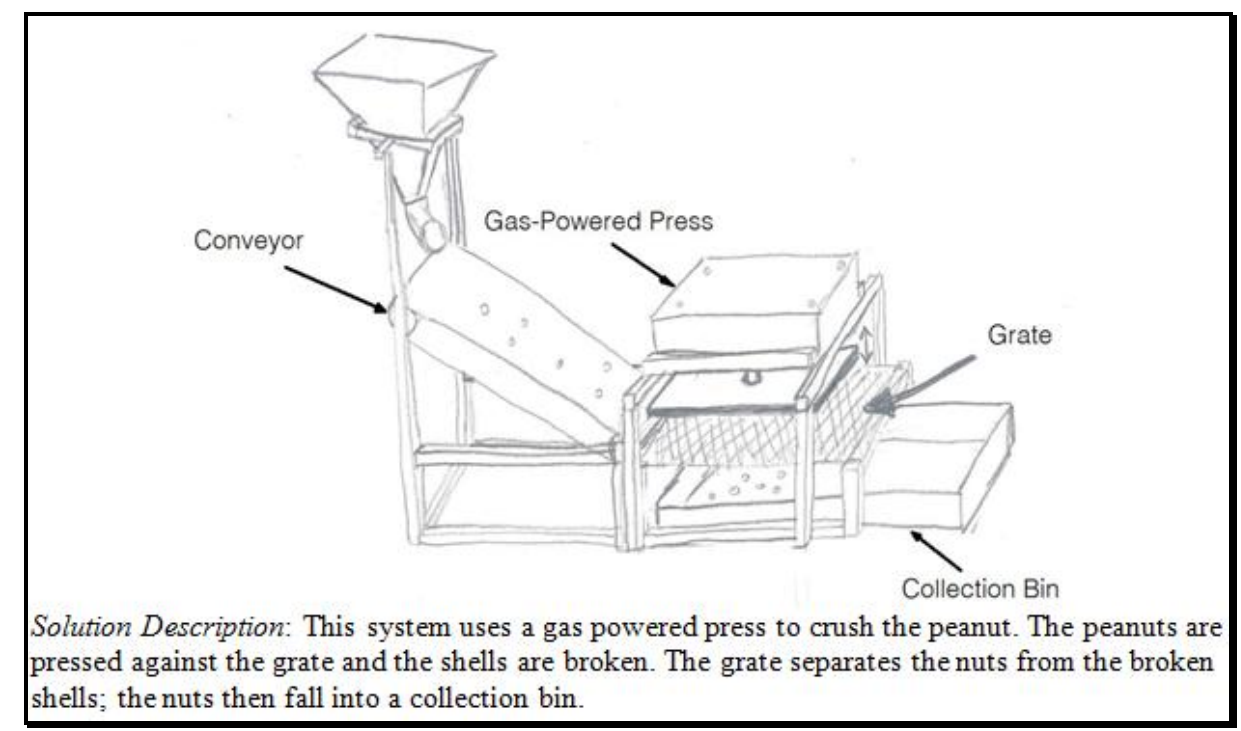

Figure 2: Sketch of example used.

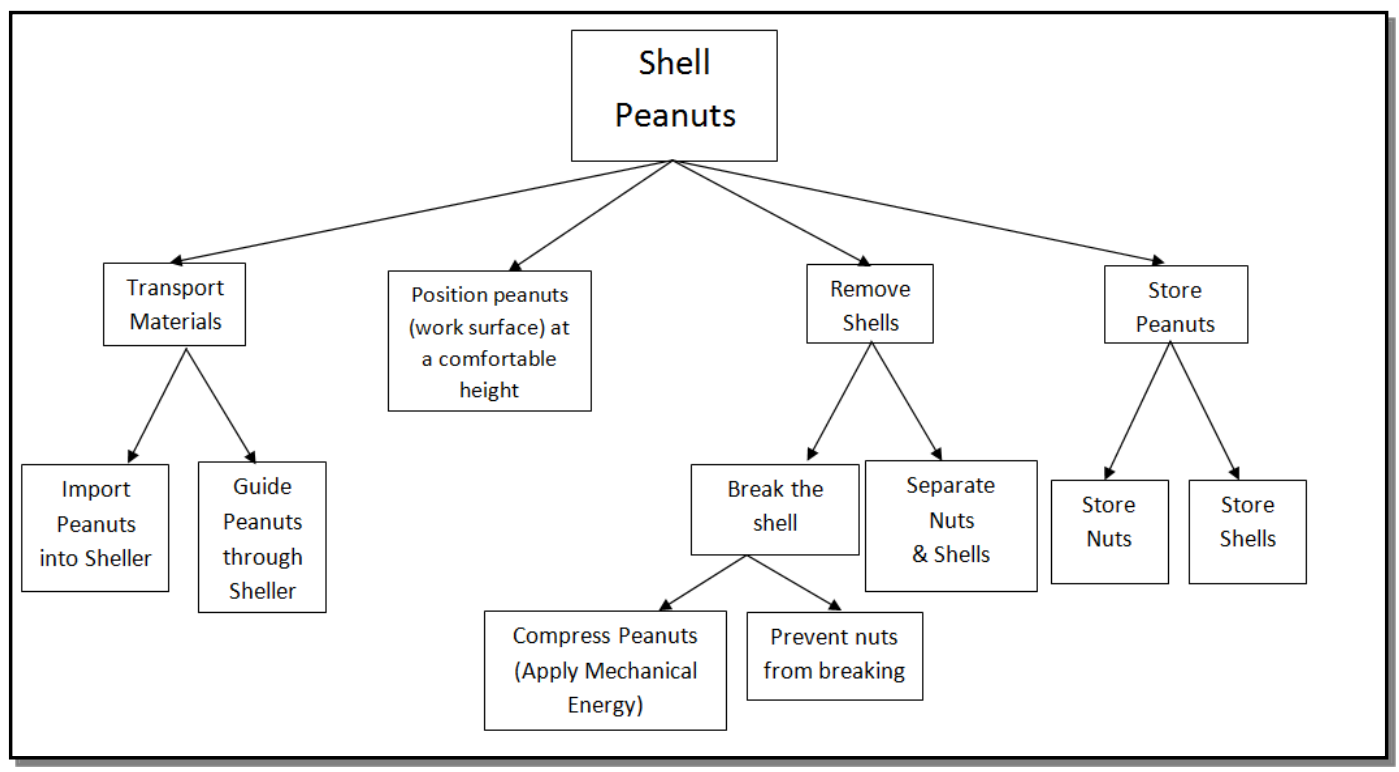

Figure 3: Function tree of example used. 

powered press sheller design (Linsey, et al., 2010), the authors chose the example based upon features commonly found in participant solutions from prior experiments. Studies show that common examples cause more fixation than novel or unusual ones (Perttula \& Sipilä, 2007), and poor examples cause more fixation than good examples (Fu, et al., 2010). In the context of the problem given, the design is poor because it uses a gas-powered press, which is an unsustainable and expensive energy source that would not be effective. Since the example chosen proves to cause fixation (Fu, et al., 2010; Linsey, et al., 2010; Viswanathan \& Linsey, 2013a, 2013b, 2013c), we want to determine how function trees may help to reduce this fixation. Table 1 shows the features within the gas-powered peanut sheller example that was provided to the participants.

Table 1: Functions of the example solution (Gas-powered press peanut sheller).

\begin{tabular}{|c|c|}
\hline \multirow{2}{*}{ Function } & $\begin{array}{c}\text { Features from } \\
\text { Example }\end{array}$ \\
\hline [Material] & \\
\hline guide & sloped surface \\
\cline { 2 - 2 } & conveyor \\
\hline import & hopper \\
\hline remove (shell) & crushing plate \\
\hline separate (nut and \\
broken shell)
\end{tabular}

\subsection{Experimental Procedure}




\section{EVALUATION METRICS}

To measure fixation, creativity, and the overall effectiveness of the solutions generated, six metrics were used: quantity of non-redundant ideas, number of repeated example features, percentage of example features used, quality of concepts, novelty of concepts, variety of concepts, and percentage of solutions using a gas engine. Four of these metrics, the quantity (non-redundant), quality, novelty, and variety of ideas are based on definitions proposed by Shah, et al. (2000), and further developed by Linsey et al. (2011).

For the purpose of this study, it is necessary to address important additional terminology and notions. An idea is defined as a feature of the generated solutions that solves at least one function in the functional basis (Linsey, et al., 2005; Linsey, et al., 2010). This functional basis or functional list of the example was not provided to the participants during the experiment, but was only used post-hoc for data coding and analysis. The terms idea and feature will be used 
interchangeably throughout this paper. Another term to address is a design concept, which refers to each solution that a participant generates in order to solve the design task.

Each of the participants' concepts were broken down into features and scored using the aforementioned metrics. To ensure the reliability of the metrics, two independent raters performed an inter-rater agreement and determined a Pearson's or Cohen's Kappa correlation. The raters used Table 1 as a guideline in order to determine the features copied from the example. We performed the inter-rater agreement on $50 \%$ of the data for all metrics (i.e. one rater rated $100 \%$ of the data, and a second rater rated $50 \%$ of the same data). We report the agreement results with the definition of each metric that follow. We also note that previous studies demonstrate that independent experts with domain knowledge can reliably assess quantity and quality of ideas (Linsey, et al., 2011), as well as the creativity (novelty and variety) in engineering design (Christiaans, 1992, 2002; Kudrowitz \& Wallace, 2013; Linsey, et al., 2011; Linsey, et al., 2005; Viswanathan \& Linsey, 2012a; Viswanathan \& Linsey, 2013d). A detailed description of the metrics used and evaluation performed is provided below.

\subsection{Quantity of Non-Redundant Ideas}

This measure of fixation gauges how a participant's ideas are limited because of exposure to an example. It measures the quantity of ideas generated by the participants across all participant solutions and subtracts out ideas taken from the example along with any repeated ideas. The ideas from the example were removed for all conditions, including the control group (the different conditions were analyzed blindly and the same analysis was done on all conditions). The control condition used will be a baseline to measure fixation. If the participants in the conditions that incorporate examples fail to produce as many non-redundant ideas as the participants in the control condition, then fixation is indicated. We obtained a Pearson's correlation of 0.83 , which shows the measure is reliable.

\subsection{Number of Repeated Example Features}

This metric is another measure of fixation and assesses how many ideas the participants use from the example. The control condition acts as a baseline for measuring fixation in this metric. If the participants in the conditions that incorporate the example incorporate more ideas from the example than the control group, then fixation to the example is indicated. The Pearson's correlation for this metric is 0.80 , which shows the measure is reliable.

\subsection{Percentage of Example Features Used}


This metric measures fixation to features of the example given to the participants. It is measured in the same way as the Number of Repeated Example Features metric but is calculated as a percentage of the total number of the participant's non-redundant ideas (i.e. percentage of example features used $=$ number of example features used in the solution/total number of features in the example). The Pearson's correlation for this metric is the same as the number of repeated example features metric.

\subsection{Quality of Ideas}

Quality is measured based on the feasibility of the design concepts and how well it meets design specifications or customer needs (Shah, Smith, \& Vargas-Hernandez, 2003). A three-point rating scale developed by Linsey et al. (2011) measures the quality of design concepts generated. A score of zero is given for designs that are not technically feasible or do not meet any of the customer needs. A score of one is given if the design partially meets the customer needs (1-3 customer needs). A score of two is given for designs that meet most or all of the customer needs (4-5 customer needs). A Cohen's Kappa of 0.57 was obtained. According to Clark-Carter (1997), this Cohen's Kappa value is an acceptable level of agreement.

\subsection{Novelty}

Novelty measures how unusual or unexpected a feature is when compared to those produced by other participants (Nelson, Wilson, Rosen, \& Yen, 2009; Shah, et al., 2003). For this metric, each idea is sorted into bins, and the novelty is calculated as one minus the frequency of ideas in a bin (Linsey, et al., 2005; Viswanathan \& Linsey, 2012a). For this metric, a participant's design solutions may be mapped to one or more bins. See Linsey et al. (2011) for more details on the bin sorting procedure for the novelty (and variety) scores. Equation 1 shows the formula used for novelty. The Pearson's correlation is 0.95 .

$$
\begin{aligned}
& \text { Novelty }=1-\text { Frequency of Ideas } \\
& \text { Novelty }=1-\frac{\# \text { of ideas in a bin }}{\text { Total \# of ideas per participant }}
\end{aligned}
$$

\subsection{Variety}

Variety measures the solution space explored during the idea generation process (Nelson, et al., 2009; Shah, et al., 2003). The variety is calculated as the number of bins a participant's ideas occupy divided by the total number of bins (Linsey, et al., 2011; Viswanathan \& Linsey, 2012a) . Equation 2 provides the given formula. The Pearson's correlation is 0.92 . 


$$
\text { Variety }=\frac{\# \text { of bins a participant's ideas occupy }}{\text { Total \# of bins }}
$$

\subsection{Percentage of Solutions Using a Gas Engine}

This metric measures the fixation to a poor or negative feature of an example. As participants generate ideas, a percentage of their design concepts will incorporate features found in the example provided to them. In this particular experiment, the gas-powered press appears as an energy source in the sketch representation. The number of design concepts utilizing this design features divided by the total number of design concepts generated and multiplied by 100 results in the percentage of solutions with the poor design feature. 


\section{RESULTS}

Non-parametric Kruskal-Wallis tests were performed on the data in this experiment because the data does not satisfy the normality and homogeneity of variance requirements; therefore, oneway parametric analysis of variance (ANOVA) results would not be reliable. Additionally, pairwise a-priori comparisons using Mann-Whitney tests were employed, which are equivalent to ttests for non-parametric data. A summary of these results is given in Table 2.

\subsection{Quantity of Non-Redundant Ideas}

Figure 4 shows the results from the Quantity of Non-Redundant Ideas metric. The KruskalWallis test results in $\chi^{2}=2.19, \mathrm{df}=3, p=0.083$, indicating that fixation is present in the sketch condition. Moreover, comparisons between each experimental condition yield different results. When comparing the sketch condition and the control condition, there is a statistically significant difference (Mann-Whitney test, $\mathrm{U}(3)=79, \mathrm{Z}=-1.394, p=0.076)$. None of the other conditions show statistically significant differences when compared to the control. Comparing the sketch condition to the function tree condition, we see that there is a significant difference (MannWhitney test, $\mathrm{U}(3)=83.5, \mathrm{Z}=-1.21, p=0.087$ ), all other comparisons are insignificant. These results support that while the sketch condition induces fixation, function trees alone do not, since there is no difference in fixation effects when comparing the function tree to the control. Moreover, when function trees are combined with sketches, it appears to mitigate the fixation effect of the sketches alone, i.e. the fixation that occurs when the sketch alone is presented is reduced when the function tree is added. These results support Hypothesis 1, which stated that function trees would reduce fixation compared to sketch representations. 


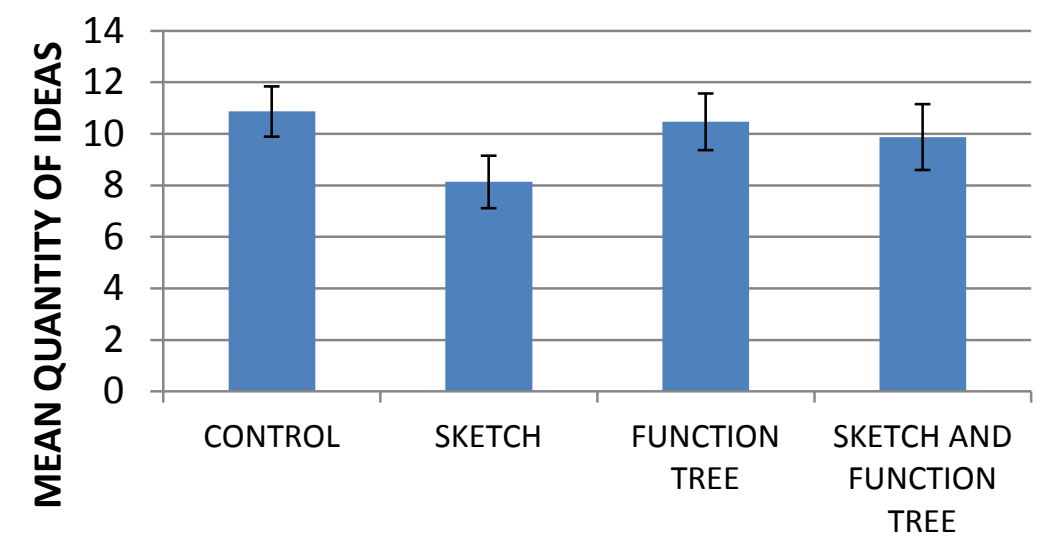

EXPERIMENT CONDITION

Figure 4: The mean quantity of non-redundant ideas across conditions. All error bars show $( \pm 1)$ standard error.

\subsection{Number of Repeated Example Features and Percentage of Example Features Used}

The Repeated Example Features and the Percentage of Example Features Used metrics present similar results as the Quantity of Ideas metric. All three of these metrics are indicators of fixation. For this particular experiment, it is important to note that we cannot compare all experimental conditions against each other using the Repeated Example Features and the Percentage of Example Features Used metrics. In this case, the sketch and the function tree conditions cannot be compared. Since participants within the function tree condition received only the function of the example without the means or features, their use of an example feature does not necessarily indicate fixation to the example. Rather, this indicates their fixation to features required to meet the functional need of the design problem. The function tree condition in this metric acts as a control for examining the benefits of having a sketch and a function tree together during idea generation. From Figure 5, we see that fixation is present for the sketch and the sketch \& function tree conditions; the Mann-Whitney test comparing the control to the two conditions respectively are $\mathrm{U}(3)=22.5, \mathrm{Z}=-3.748, p<0.001$ and $\mathrm{U}(3)=16, \mathrm{Z}=-4.122, p<$ 0.001. When we compare the control to the function tree condition, there is no statistically significant difference $(\mathrm{U}(3)=51.5, \mathrm{Z}=-2.551, p=0.127)$. Utilizing a function tree as a stimulus compared to when no stimulus is used does not influence the results. We cannot discern a statistically significant difference between a function tree and the control group; there appears to be a tendency toward fixation with function trees that merits further investigation. This is further reinforced by the sketch and function tree combination. The function tree neither causes nor 
reduces fixation. Additionally, these results illustrate that the greatest amount of fixation is present in the sketch \& function tree condition.

There are statistically significant differences when comparing the sketch $\&$ function tree condition to both the sketch condition and the function tree condition $(\mathrm{U}(3)=87, \mathrm{Z}=-1.31, p=$ 0.031 and $\mathrm{U}(3)=37, \mathrm{Z}=-3.3-2, p=0.001$ respectively). It appears that combining a sketch \& function tree actually reinforces fixation to the features of the example. The percentage of example features copied, Figure 6, shows similar results. The Kruskal-Wallis test results for the two metrics are $\chi^{2}=28.46, \mathrm{df}=3, p<0.001$ and $\chi^{2}=30.4, \mathrm{df}=3, p<0.001$, respectively.

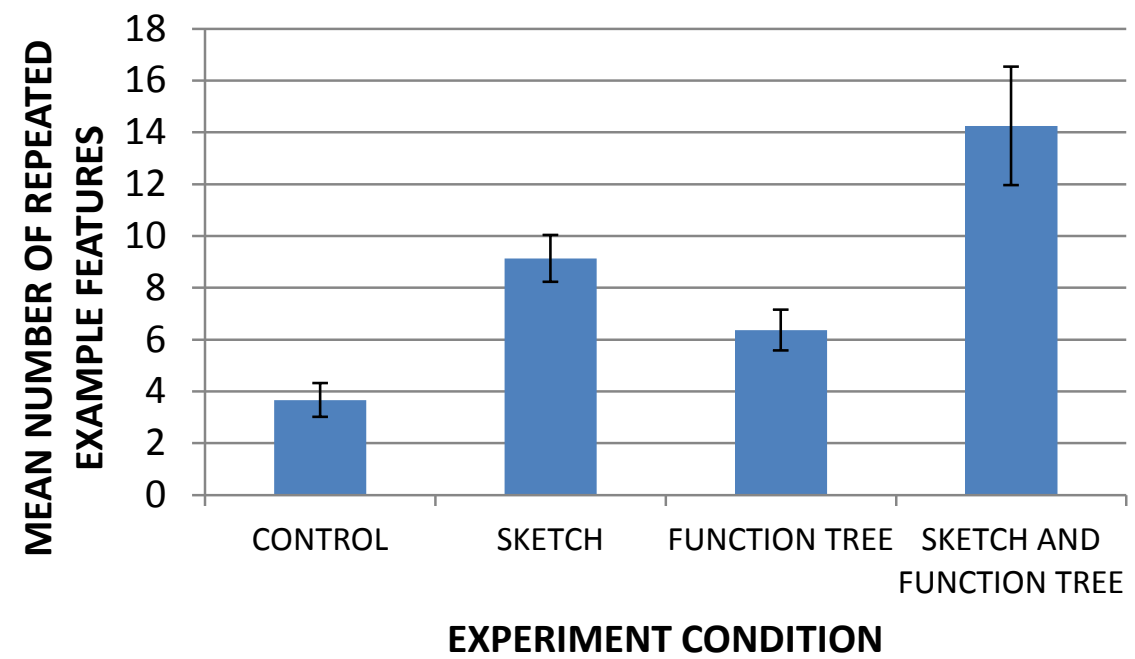

Figure 5: The mean number of repeated example features across conditions. All error bars show $( \pm 1)$ standard error.

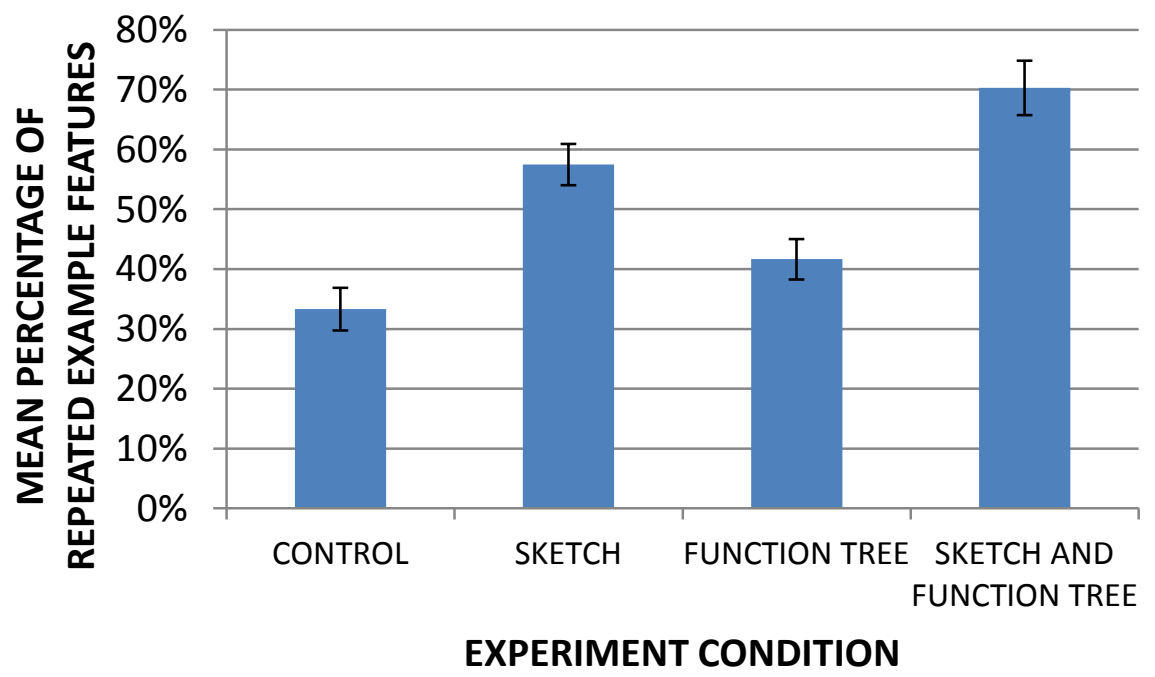

Figure 6: The mean percentage of example features used across conditions. All error bars show $( \pm 1)$ standard error. 


\subsection{Quality of Design Concepts}

The results from the Quality of Design Concepts, displayed in Figure 7, show that the function tree condition has the highest quality score and that there is a statistically significant difference when compared to the other three experimental conditions. The Mann-Whitney results are $\mathrm{U}(3)=77.5, \mathrm{Z}=-1.485, p=0.079 ; \mathrm{U}(3)=88.5, \mathrm{Z}=-1.015, p=0.083$; and $\mathrm{U}(3)=76.5, \mathrm{Z}=$ 1.737, $p=0.082$ for the control, sketch, and sketch \& function tree conditions, respectively. Additionally, no statistically significant differences exist when comparing the other conditions to each other, i.e. control, sketch, and sketch and function tree. The Kruskal-Wallis test gives $\chi^{2}=$ $3.57, \mathrm{df}=3, p=0.080$ and shows that a function tree representation increases quality unlike presenting participants with a sketch or even a sketch in combination with a function tree; Hypothesis 2 is supported.

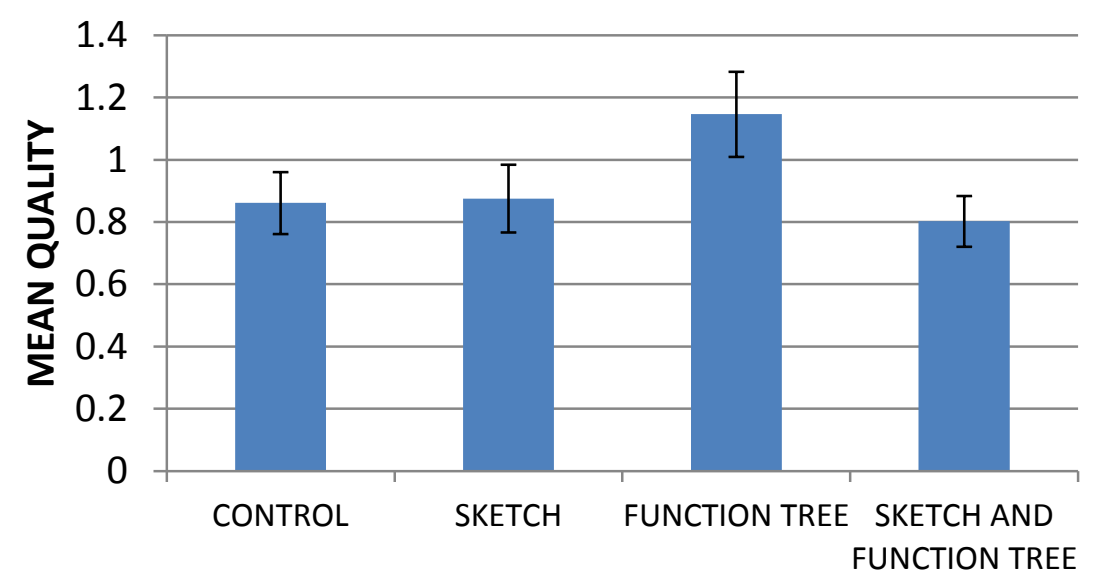

EXPERIMENT CONDITION

Figure 7: The mean quality of design concepts across conditions. All error bars show $( \pm 1)$ standard error.

\subsection{Novelty and Variety}

The novelty and variety results are shown in Figure 8 and Figure 9, respectively. There are no significant differences when comparing conditions for the two metrics. The Kruskal-Wallis test gives $\chi^{2}=0.762, \mathrm{df}=3, p=0.859$ for the novelty scores and $\chi^{2}=0.107, \mathrm{df}=3, p=0.991$ for the variety scores. This reveals the possibility that the novelty and variety metrics may lack sensitivity. Prior studies (Linsey, et al., 2011; Viswanathan \& Linsey, 2013a, 2013d) have also 
not seen differences in novelty and variety in idea generation studies. Cardoso and BadkeSchaub (Cardoso \& Badke-Schaub, 2011) also saw no differences in originality for line drawing compared to photos.

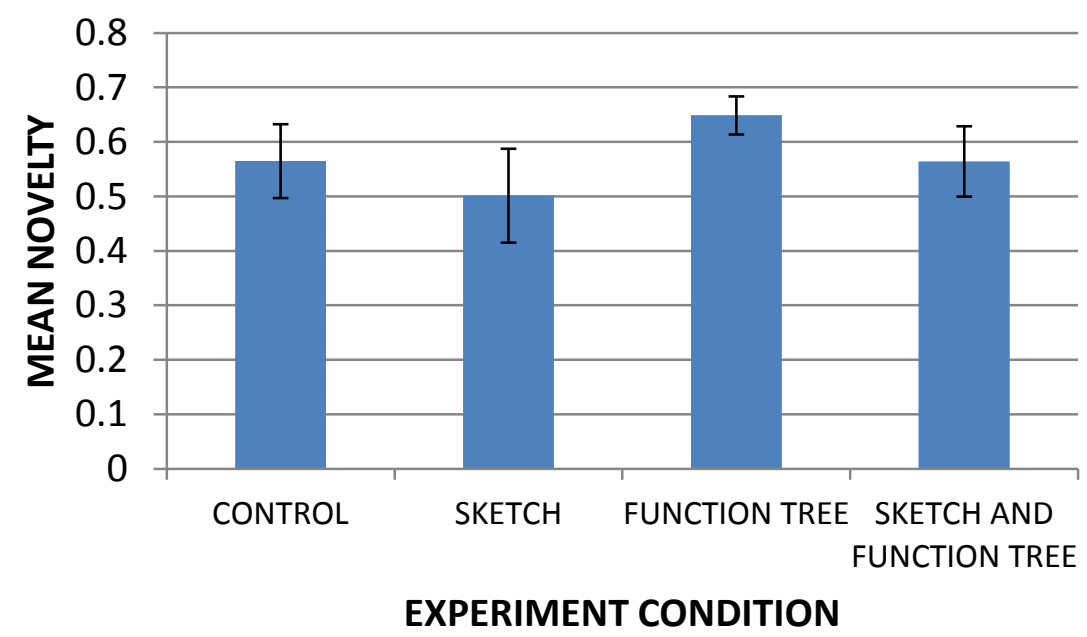

Figure 8: The mean novelty across conditions. All error bars show $( \pm 1)$ standard error.

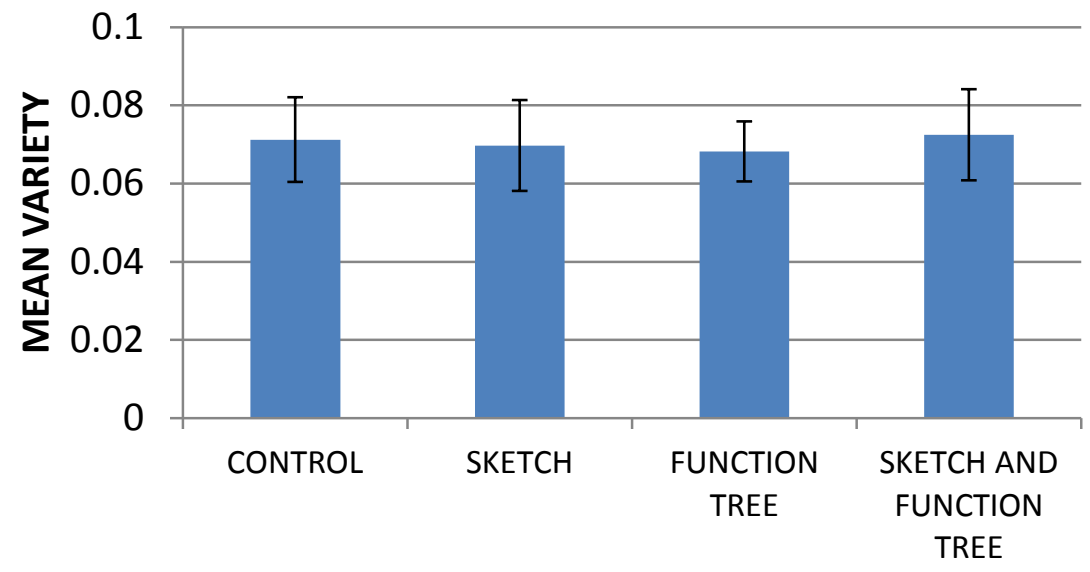

EXPERIMENT CONDITION

Figure 9: The mean variety across conditions. All error bars show $( \pm 1)$ standard error. 


\subsection{Percentage of Solutions Using a Gas Engine}

From Figure 10, we see that sketch and sketch \& function tree conditions used gas engines as an energy source for their design solutions. The control and function tree experiment did not use any gas engines in their designs. This was an expected result since the control group did not receive the example with a function tree. The function tree did not include the means of crushing, i.e., the gas-powered press. Though the sketch $\&$ function tree condition use a higher percentage of gas-powered solutions compared to the sketch condition, the difference is not significant $(p=$ 0.21 ). These results show evidence of fixation to the type of energy source in the example. The presence of the function tree in the sketch \& function tree condition does not appear to help break fixation.

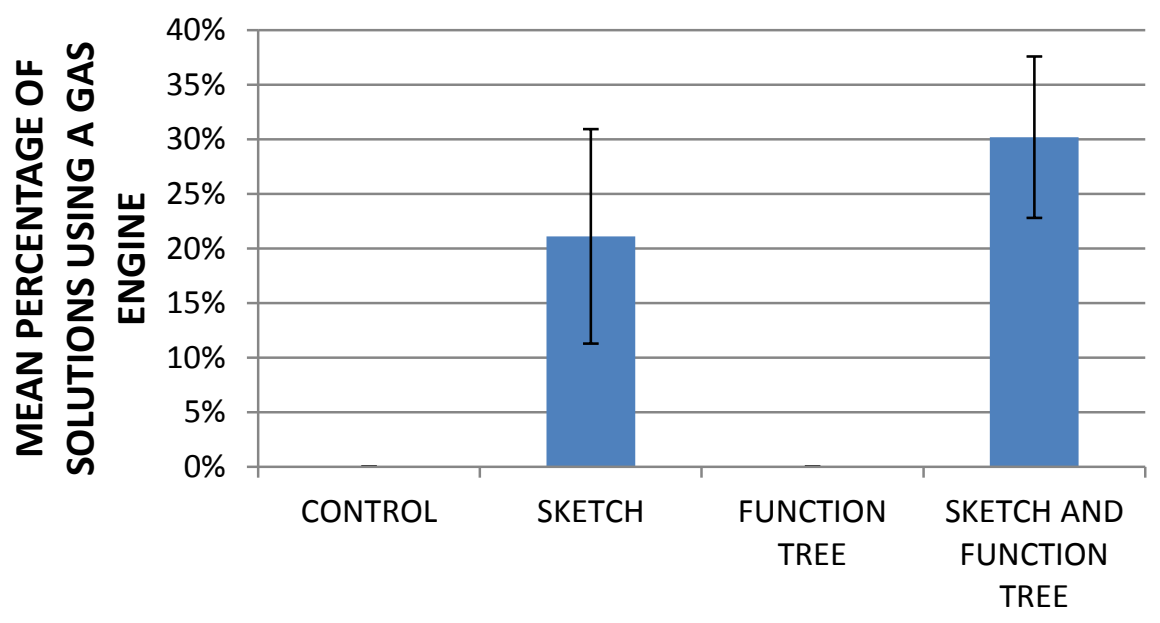

EXPERIMENT CONDITION

Figure 10: The mean percentage of solutions using a gas-powered press across conditions. All error bars show $( \pm 1)$ standard error. 
Table 2: Kruskal-Wallis and Mann-Whitney Results

\begin{tabular}{|l|r|r|r|r|}
\hline Quantity & Chi-Sq & \multicolumn{1}{|l|}{ p } & df & \\
\hline & 2.193 & 0.069 & & \\
\hline & & & & \\
\hline & Control & SKETCH & FT & SKETCH + FT \\
\hline Control & & 0.038 & 0.983 & 0.634 \\
\hline SKETCH & & & 0.043 & 0.451 \\
\hline FT & & & & 0.677 \\
\hline SKETCH + FT & & & & \\
\hline
\end{tabular}

\begin{tabular}{|l|r|r|r|r|}
\hline Quality & Chi-Sq & p & df & \\
\hline & 3.576 & 0.08 & 3 & \\
\hline & & & & \\
\hline & Control & SKETCH & FT & SKETCH + FT \\
\hline Control & & 0.862 & 0.079 & 0.793 \\
\hline SKETCH & & & 0.083 & 0.607 \\
\hline FT & & & & 0.082 \\
\hline SKETCH + FT & & & & \\
\hline
\end{tabular}

\begin{tabular}{|l|r|r|r|r|r|}
\hline \# Example Fts & Chi-Sq & p & df & \\
\hline & 28.464 & & & 3 & \\
\hline & & & & \\
\hline & Control & SKETCH & FT & SKETCH + FT \\
\hline Control & & & 0 & 0.127 & 0 \\
\hline SKETCH & & & NA & 0.031 \\
\hline FT & & & & 0.001 \\
\hline SKETCH + FT & & & & \\
\hline
\end{tabular}

\begin{tabular}{|l|r|r|r|r|}
\hline Novelty & \multicolumn{1}{|l|}{ Chi-Sq } & $\mathrm{p}$ & df & \\
\hline & 0.762 & 0.859 & & \\
\hline & & & & \\
\hline & Control & SKETCH & FT & SKETCH + FT \\
\hline Control & & 0.816 & 0.52 & 0.935 \\
\hline SKETCH & & & 0.472 & 0.809 \\
\hline FT & & & & 0.486 \\
\hline SKETCH + FT & & & & \\
\hline
\end{tabular}

\begin{tabular}{|c|c|c|c|c|}
\hline \% Example Fts & Chi-Sq & \multicolumn{2}{|r|}{ df } & \\
\hline & 30.438 & 0 & 3 & \\
\hline & & & & \\
\hline & Control & SKETCH & FT & SKETCH + FT \\
\hline Control & & 0 & 0.185 & 0 \\
\hline SKETCH & & & $\mathrm{NA}$ & 0.023 \\
\hline \begin{tabular}{|l|} 
FT \\
\end{tabular} & & & & 0 \\
\hline SKETCI & & & & \\
\hline
\end{tabular}

\begin{tabular}{|l|r|r|r|r|}
\hline Variety & Chi-Sq & \multicolumn{1}{l|}{$\mathrm{p}$} & df & \\
\hline & 0.107 & 0.991 & & 3 \\
\hline & & & & \\
\hline & Control & SKETCH & FT & SKETCH + FT \\
\hline Control & & 0.816 & 0.932 & 0.935 \\
\hline SKETCH & & & 0.799 & 0.809 \\
\hline FT & & & & 0.87 \\
\hline SKETCH + FT & & & & \\
\hline
\end{tabular}

\begin{tabular}{|c|c|c|c|c|}
\hline Pct Gas Powered & Chi-Sq & $p$ & $d f$ & \\
\hline & 20.688 & 0 & 3 & \\
\hline & Control & J LᄃTCH & & \\
\hline Control & & 0.035 & 1 & $c$ \\
\hline SKETCH & & & 0.035 & $0.20 \mathrm{~s}$ \\
\hline FT & & & & $c$ \\
\hline SKETCH + & & & & \\
\hline
\end{tabular}

\section{DISCUSSION}

The results from this experiment provide important and interesting results concerning the role of function trees in idea generation. We see from the results in this paper that function trees do not cause fixation. The results also further support that sketch representations cause fixation, which has also been seen in other fixation studies.

The results from the quantity of non-redundant features show that function trees reduce fixation compared with sketches; this supports Hypothesis 1 which stated the same. This is a new result in the area of fixation and shows that to reduce fixation, and if the choice is offered, functions are preferable over sketches. Furthermore, we show that while function tree 
representations do not induce fixation, they effectively mitigate some aspects of fixation when used in conjunction with sketch representation. These results demonstrate that for ideation purposes, the two representations combined together in a condition may provide the benefits of each, while negating fixation effects with respect to the number of ideas generated.

When we look at fixation to the features of the example, we examine that there is no significant difference between the control and function tree condition, which indicates that functional representations of examples are not the cause of fixation. This is an important result because as discussed earlier in the paper, this has been conjectured by engineers and researchers, but has never been scientifically or experimentally tested. This is the first experiment to show proof of this.

Looking at the features copied from the example and comparing the sketch with the sketch \& function tree condition, we determine that the participants in the sketch \& function tree condition fixate more to the features of the example, compared to just the sketch condition alone. Unlike with the number of ideas, a combination of a sketch and function tree does reinforce fixation to the features of the example. Thus, while we get more ideas, our ideas also include more features from the example. Designers, upon reviewing the function tree and seeing the functions that need to be met, gravitate towards trying to meet and satisfy those functions by using similar features from the example that they are viewing simultaneously. We witness this same trend when comparing the function tree to the sketch $\&$ function tree condition: feature fixation increases when a sketch and function tree are both present. These results indicate that the benefits of reducing feature fixation arise when only presenting the function tree alone; the addition of a sketch to the function tree promotes fixation.

The quality results show another benefit of the function tree: the quality score for the design concepts in the function tree condition is higher than all other three conditions, supporting Hypothesis 2. This occurs because the function tree clearly and succinctly defines all the functions that need to be met without introducing specific or extraneous features as a sketch representation does. These results support our second hypothesis that function trees increase design quality.

The novelty and variety scores show no differences across all conditions. It appears that all conditions explored the design space to the same degree. The percentage of energy sources using the gas engine metric validates fixation to the gas engine in the sketch and sketch \& function tree 
conditions with no significant differences between the two. The combination condition of the sketch \& function tree did appear to break the fixation to this poor feature of the example.

The results from this experiment show new results pertaining to the use of function trees in engineering design. Function trees of examples more effectively reduce idea fixation than sketch representations for the same example. Function trees alone, also do not cause fixation to a designer's ideas or to the features of the example. While function trees do not break fixation, they do produce a higher quality of solution concepts. We initially believed that providing more information to designers, i.e., a sketch and a function tree together, would increase the benefits provided by the function tree. We were surprised to see from the results that this is not the case and that the combination of these representations in an idea generation task increases feature fixation while also negating quality benefits.

The results from this experiment indicate that function trees provide some quality and fixation breaking benefit for idea generation procedures, and that to some extent they may help avoid fixation and improve the quality of generated ideas and solutions in the conceptual design stage. The results also sound a note of caution, in that one must be careful in the design of support tools and environments to understand the interactions among representations, which can be both positive (in the case of function trees mitigating sketch idea fixation effects), and negative (in the case of function trees increasing the sketch feature fixation effects).

\section{CONCLUSIONS AND FUTURE WORK}

The experiment performed in this study investigated how the representations of an example given during idea generation affects and reflects on design fixation. In the experiment, we explored function tree and sketch representations while using a poor design example. We found that function trees are not fixation inducing, and that combining a sketch with function trees tends to reduce idea fixation, while reinforcing and increasing example feature fixation.

The results from this experiment provide greater insight into the dynamics of fixation, specifically on how the use and incorporation of various representations affects fixation during the conceptual stages of design. Further studies to investigate other types of representations presented alone and in combination are already in progress. The apparent lack of sensitivity in the novelty and variety metrics is also interesting and will be further studied in upcoming research. 


\section{LIMITATIONS}

The data for this paper were collected from students in the same course given during two consecutive semesters. The same instructor taught classes, and the same material was taught during both semester. It is unlikely that this semester split affected the results in anyway. There were no significant differences comparing the results from both semesters with each other (after all the data had been blindly analyzed).

The students participating in the study were not calibrated with a pre-test to assess any differences in mechanical aptitude. It was assumed that since they were all in the same class their knowledge and aptitude would be at the same level .

\section{Acknowledgements}

Partial support for this work was provided by the National Science Foundation Award Nos. CMMI-100095 and CMMI-1322335. Any opinions, findings, and conclusions or recommendations expressed in this material are those of the authors and do not necessarily reflect the views of the National Science Foundation. We are grateful to the anonymous reviewers for providing feedback and advice that greatly strengthened this paper. 


\section{REFERENCES}

Adler, A., \& Davis, R. (2007). Speech and Sketching for Multimodal Design. In ACM SIGGRAPH 2007 Courses (pp. 14): ACM.

Altshuller, G. S. (1984). Creativity as an Exact Science: The Theory of the Solution of Inventive Problems. New York: Gordon \& Breach Science Publishing.

Ashton, R. H. (1976). Cognitive Changes Induced by Accounting Changes: Experimental Evidence on the Functional Fixation Hypothesis. Journal of Accounting Research, 1-17.

Brandis, J. (2012). The Full Belly Project. In (Vol. 2012).

Brown, V., Tumeo, M., Larey, T. S., \& Paulus, P. B. (1998). Modeling Cognitive Interactions During Group Brainstorming. Small Group Research, 29, 495-526.

Caldwell, B. W., \& Mocko, G. M. (2012). Validation of Function Pruning Rules Through Similarity at Three Levels of Abstraction. Journal of Mechanical Design, 134, 041008.

Cardoso, C., \& Badke-Schaub, P. (2011). The Influence of Different Pictorial Representations During Idea Generation. The Journal of Creative Behavior, 45, 130-146.

Cardoso, C., Badke-Schaub, P., \& Luz, A. (2009). Design Fixation on Non-Verbal Stimuli: The Influence of Simple vs Rich Pictorial Information on Design Problem Solving. In ASME International Design Engineering Technical Conference \& Computers and Information in Engineering Conference. San Diego, CA.

Casakin, H., \& Goldschmidt, G. (1999). Expertise and the use of visual analogy: Implications for design education. Design Studies, 20, 153-175.

Christensen, B. T., \& Schunn, C. D. (2005). The Relationship of Analogical Distance to Analogical Function and Pre-inventive structure: The case of Engineering Design. Creative Cognition: Analogy and Incubation, 35, 29-38.

Christiaans, H. H. (1992). Creativity in Design: The Role of Domain Knowledge in Designing. Unpublished Doctoral Dissertation, Deflt University of Technology, Delft, Netherlands.

Christiaans, H. H. (2002). Creativity as a Design Criterion. Communication Research Journal, 14, 41-54.

Condoor, S., \& LaVoie, D. (2007). Design Fixation: A Cognitive Model. In International Conference on Engineering Design, ICED '07. Paris, France.

Connors, C. (2008). Jock Brandis Makes Life Better With Peanuts. In: Makezine Blog.

Contero, M., Varley, P., Aleixos, N., \& Naya, F. (2009). Computer-Aided Sketching as a Tool to Promote Innovation in the New Product Development Process. Computers in Industry, 60, 592-603.

Coskun, H., Paulus, P. B., Brown, V., \& Sherwood, J. J. (2000). Cognitive stimulation and problem presentation in idea-generating groups. Group Dynamics: Theory, Research, and Practice, 4, 307.

Dorst, K. (2003). The Problem of Design Problems. Expertise in design, 135-147.

Dugosh, K. L., \& Paulus, P. B. (2005). Cognitive and Social Comparison Processes in Brainstorming. Journal of Experimental Social Psychology, 41, 313-320.

Duncker, K., \& Lees, L. S. (1945). On Problem-Solving. Psychological monographs, 58, i.

Dym, C. L., Little, P., Orwin, E. J., \& Spjut, R. E. (2004). Engineering Design: A Project-Based Introduction: Wiley New York.

Eckert, C. (2013). That Which is Not Form: The Practical Challenges in using Functional Concepts in Design. Artificial Intelligence for Engineering Design, Analysis and Manufacturing, 27, 217-231.7 
Fish, J., \& Scrivener, S. (1990). Amplifying the Mind's Eye: Sketching and Visual Cognition. Leonardo, 23, 117-126.

Fu, K., Cagan, J., \& Kotovsky, K. (2010). Design Team Convergence: The Influence of Example Solution Quality. Journal of Mechanical Design, 132, 111005.

Goel, V. (1995). Sketches of Thought: MIT Press.

Goldschmidt, G. (1991). The Dialectics of Sketching. Creativity research journal, 4, 123-143.

Goldschmidt, G. (1994). On Visual Design Thinking: The Vis Kids of Architecture. Design Studies, 15, 158-174.

Goldschmidt, G. (2007). To See Eye to Eye: The Role of Visual Representations in Building Shared Mental Models in Design Teams. CoDesign, 3, 43-50.

Goldschmidt, G., \& Smolkov, M. (2006). Variances in the Impact of Visual Stimuli on Design Problem Solving Performance. Design Studies, 27, 549-569.

Grenier, A. L. (2008). Conceptual Understanding and the Use of Hand-Sketching in Mechanical Engineering Design. Unpublished Masters Thesis, University of Maryland, College Park, Maryland.

Hannah, R., Joshi, S., \& Summers, J. D. (2012). A user study of interpretability of engineering design representations. Journal of Engineering Design, 23, 443-468.

Hartson, H. R. (2003). Cognitive, Physical, Sensory, and Functional Affordances in Interaction Design. Behaviour \& Information Technology, 22, 315-338.

Hirtz, J., Stone, R. B., McAdams, D. A., Szykman, S., \& Wood, K. L. (2002). A Functional Basis for Engineering design: Reconciling and Evolving Previous Efforts. Research in engineering Design, 13, 65-82.

Hostetter, A. B., \& Alibali, M. W. (2008). Visible Embodiment: Gestures as Simulated Action. Psychonomic bulletin \& review, 15, 495-514.

Jansson, D., Condoor, S., \& Brock, H. (1993). Cognition in Design: Viewing The Hidden Side of the Design Process. Environment and Planning B: Planning Design, 20, 257-271.

Jansson, D., \& Smith, S. (1991). Design Fixation. Design Studies, 12, 3-11.

Jonson, B. (2002). Sketching Now. International Journal of Art \& Design Education, 21, 246253.

Jonson, B. (2005). Design Ideation: The Conceptual Sketch in the Digital Age. Design Studies, 26, 613-624.

Kavakli, M., \& Gero, J. S. (2001). Sketching as Mental Imagery Processing. Design Studies, 22, 347-364.

Kavakli, M., \& Gero, J. S. (2002). The Structure of Concurrent Cognitive Actions: A Case Study on Novice and Expert Designers. Design Studies, 23, 25-40.

Kiriyama, T., \& Yamamoto, T. (1998). Strategic Knowledge Acquisition: A Case Study of Learning Through Prototyping. Knowledge-Based Systems, 11, 399-404.

Kokotovich, V., \& Purcell, T. (2000). Mental Synthesis and Creativity in Design: An Experimental Examination. Design Studies, 21, 437-449.

Kudrowitz, B. M., \& Wallace, D. (2013). Assessing the Quality of Ideas from Prolific, Earlystage Product Ideation. Journal of Engineering Design, 24, 120-139. 
Larkin, J. H., \& Simon, H. A. (1987). Why a Diagram is (Sometimes) Worth Ten Thousand Words. Cognitive Science, 11, 65-100.

Liikkanen, L. A., \& Perttula, M. (2010). Inspiring design idea generation: insights from a memory-search perspective. Journal of Engineering Design, 21, 545-560.

Linsey, Clauss, E. F., Kurtoglu, T., Murphy, J. T., Wood, K. L., \& Markman, A. B. (2011). An Experimental Study of Group Idea Generation Techniques: Understanding the Roles of Idea Representation and Viewing Methods. Journal of Mechanical Design, 133, 031008.

Linsey, Green, M. G., Murphy, J., Wood, K. L., \& Markman, A. B. (2005). Collaborating to Success: An Experimental Study of Group Idea Generation Techniques. In ASME International Design Engineering Technical Conference \& Computers and Information in Engineering Conference. Long Beach, California.

Linsey, Markman, A., \& Wood, K. (2012). Design by Analogy: A Study of the WordTree Method for Problem Re-Representation. Journal of Mechanical Design, 134, 041009.

Linsey, Tseng, I., Fu, K., Cagan, J., Wood, K., \& Schunn, C. (2010). A Study of Design Fixation, its Mitigation and Perception in Engineering Design Faculty. Journal of Mechanical Design, 132, 041003.

Macomber, B., \& Yang, M. (2011). The Role of Sketch Finish and Style in User Responses to Early Stage Design Concepts. In ASME International Design Engineering Technical Conference \& Computers and Information in Engineering Conference. Washington, DC.

Manning, B. (2013). ACQ Notes. In Systems Engineering: Functional Analysis and Allocation (Vol. 2013).

McCaffrey, T. (2012a). Innovation Relies on the Obscure: A Key to Overcoming the Classic Problem of Functional Fixedness. Psychological science, 23(3), 215-218.

McCaffrey, T. (2012b). The Obscure Features Hypothesis for Innovation: One Key to Improving Performance in Insight Problems. Doctoral Dissertation. University of Massachusetts Amherst, Amherst, MA.

McCaffrey, T., \& Spector, L. (2011). How the Obscure Features Hypothesis Leads to Innovation Assistant Software. In Proceedings of the Second International Conference on Computational Creativity (pp. 120-122). Mexico City, Mexico.

McKoy, F. L., Vargas-Hernández, N., Summers, J. D., \& Shah, J. J. (2001). Influence of Design Representation on Effectiveness of Idea Generation. In ASME International Design Engineering Technical Conference \& Computers and Information in Engineering Conference. Pittsburgh, PA.

Menezes, A., \& Lawson, B. (2006). How Designers Perceive Sketches. Design Studies, 27, 571585.

Murdock, J., Szykman, S., \& Sriram, R. (1997). An Information Modeling Framework to Support Design Databases and Repositories. In ASME International Design Engineering Technical Conference \& Computers and Information in Engineering Conference (pp. 1417). Sacramento, CA.

Nelson, B. A., Wilson, J. O., Rosen, D., \& Yen, J. (2009). Refined Metrics for Measuring Ideation Effectiveness. Design Studies, 30, 737-743.

Otto, K. N., \& Wood, K. L. (2001). Product Design: Techniques in Reverse Engineering and New Product Development. New York: Prentice Hall.

Pahl, G., \& Beitz, W. (1996). Engineering design: a systematic approach. In: Springer.

Pahl, G., Beitz, W., Feldhusen, J., \& Grote, K. H. (2007). Engineering design: a systematic approach (3rd ed.): Springer. 
Pei, E., Campbell, I., \& Evans, M. (2011). A Taxonomic Classification of Visual Design Representations Used by Industrial Designers and Engineering Designers. The Design Journal, 14, 64-91.

Perttula, M., \& Liikkanen, L. (2006). Exposure Effects in Design Idea Generation: Unconscious Conformity or a Product of Sampling Probability? In Proceedings of NordDesign (pp. 42-55).

Perttula, M., \& Sipilä, P. (2007). The Idea Exposure Paradigm in Design Idea Generation. Journal of Engineering Design, 18, 93-102.

Press, D. A. (2001). Systems Engineering Fundamentals, a supplementary text (Vol. 1).

Purcell, \& Gero. (1992). Effects of Examples on the Results of a Design Activity. KnowledgeBased Systems, 5, 82-91.

Purcell, \& Gero. (1996). Design and Other Types of Fixation. Design Studies, 17, 363-383.

Reid, T. N., MacDonald, E. F., \& Du, P. (2013). Impact of Product Design Representation on Customer Judgment. Journal of Mechanical Design, 135, 091008.

Schmidt, L. C., Hernandez, N. V., \& Ruocco, A. L. (2012). Research on Encouraging Sketching in Engineering Design. Artificial Intelligence for Engineering Design, Analysis and Manufacturing, 26, 303-315.

Schrage, M. (1999). Serious Play: How the world's best companies simulate to innovate. Boston, MA: Harvard Business Press.

Shah, J. J. (1998). Experimental Investigation of Progressive Idea Generation Techniques in Engineering Design. In ASME International Design Engineering Technical Conference \& Computers and Information in Engineering Conference. Atlanta, GA.

Shah, J. J., Kulkarni, S. V., \& Vargas-Hernandez, N. (2000). Evaluation of Idea Generation Methods for Conceptual Design: Effectiveness Metrics and Design of Experiments. Journal of Mechanical Design, 122, 377-384.

Shah, J. J., Smith, S. M., \& Vargas-Hernandez, N. (2003). Metrics for Measuring Ideation Effectiveness. Design Studies, 24, 111-134.

Stacey, M., Eckert, C., \& McFadzean, J. (1999). Sketch Interpretation in Design Communication. In International Conference on Engineering Design. Munich, Germany.

Stone, R. B., Wood, K. L., \& Crawford, R. H. (2000). Using Quantitative Functional Models to Develop Product Architectures. Design Studies, 21, 239-260.

Suwa, M., \& Tversky, B. (1997). What Do Architects and Students Perceive in their Design Sketches? A Protocol Analysis. Design Studies, 18, 385-403.

Tversky, B., Suwa, M., Agrawala, M., Heiser, J., Stolte, C., Hanrahan, P., Phan, D., Klingner, J., Daniel, M. P., \& Lee, P. (2003). Sketches for Design and Design of Sketches. In U. Lindemann (Ed.), Human Behavior in Design: Individuals, Teams, Tools (pp. 79-86). Berlin: Springer.

Ullman, D. G. (1992). The Mechanical Design Process (Vol. 2): McGraw-Hill New York.

Ullman, D. G., Wood, S., \& Craig, D. (1990). The Importance of Drawing in the Mechanical Design Process. Computers \& Graphics, 14, 263-274.

Ulrich, K. T., \& Eppinger, S. D. (1995). Product design and development (Vol. 384): McGrawHill New York.

Van der Lugt, R. (2005). How Sketching Can Affect the Idea Generation Process in Design Group Meetings. Design Studies, 26, 101-122. 
Viola, N., Corpino, S., Stesina, F., \& Fioriti, M. (2012). Functional Analysis in Systems Engineering: methodology and applications. In B. Cogan (Ed.), Systems Engineering Practice and Theory (pp. 71-96).

Viswanathan, \& Linsey. (2010). Physical Models in Idea Generation - Hindrance or Help? In ASME International Design Engineering Technical Conference \& Computers and Information in Engineering Conference. Montreal, Quebec, Canada.

Viswanathan, V., \& Linsey, J. (2011). Understanding Fixation: A Study on the Role of Expertise. In International Conference on Engineering Design. Kongens Lyngby, Denmark.

Viswanathan, V., \& Linsey, J. (2012a). Physical Models and Design Thinking: A Study of Functionality, Novelty and Variety of Ideas. Journal of Mechanical Design, 134, 091004.

Viswanathan, V., \& Linsey, J. (2012b). A Study on the Role of Expertise in Design Fixation and It's Mitigation. In ASME International Design Engineering Technical Conference \& Computers and Information in Engineering Conference. Chicago, IL.

Viswanathan, V., \& Linsey, J. (2013a). Design Fixation and Its Mitigation: A Study on the Role of Expertise. Journal of Mechanical Design, 135, 051008.

Viswanathan, V., \& Linsey, J. (2013b). Examining Design Fixation in Engineering Idea Generation: The Role of Example Modality. International Journal of Design Creativity and Innovation, 1, 109-129.

Viswanathan, V., \& Linsey, J. (2013c). Mitigation of Design Fixation in Engineering Idea Generation: A Study on the Role of Defixation Instructions. In ICoRD'13 (pp. 113-124): Springer.

Viswanathan, V., \& Linsey, J. (2013d). Role of Sunk Cost in Engineering Idea Generation: An Experimental Investigation (In review). Journal of Mechanical Design, 135.

Westmoreland, S., Ruocco, A., \& Schmidt, L. (2011). Analysis of Capstone Design Reports: Visual Representations. Journal of Mechanical Design, 133, 051010.

Wiley, J. (1998). Expertise as Mental Set: The Effects of Domain Knowledge in Creative Problem Solving. Memory \& Cognition, 26, 716-730.

Yang, M. C. (2009). Observations on Concept Generation and Sketching in Engineering Design. Research in engineering Design, 20, 1-11.

Yang, M. C., \& Cham, J. G. (2007). An Analysis of Sketching Skill and its Role in Early Stage Engineering Design. Journal of Mechanical Design, 129, 476-482.

Youmans, R. J. (2011). The Effects of Physical Prototyping and Group Work on the Reduction of Design Fixation. Design Studies, 32, 115-138.

Zha, X. F., \& Howlett, R. J. (2006). Integrated Intelligent Systems for Engineering Design (Vol. 149): IOS Press. 